\title{
Retraction Note: Mechanical properties of basin loess based on image recognition and aerobic exercise data monitoring of athletes
}

\author{
Chenguang Sun ${ }^{1} \cdot$ Qin Chen $^{2}$
}

Published online: 22 November 2021

C) Saudi Society for Geosciences 2021

Retraction Note: Arabian Journal of Geosciences (2021)

14: 1758

https://doi.org/10.1007/s12517-021-08002-5

The Editor-in-Chief and the Publisher have retracted this article because the content of this article is nonsensical. The peer review process was not carried out in accordance with the Publisher's peer review policy. Author Chenguang Sun has not responded to correspondence regarding this retraction. The Publisher has not been able to obtain a current email address for author Qin Chen.

The online version of the original article can be found at https:// doi.org/10.1007/s12517-021-08002-5

Chenguang Sun

chenguang0617@yeah.net

1 Postgraduate School, Chengdu Sport University, Chengdu 610041, Sichuan, China

2 Ekg Room, AVIC 363 Hospital, Chengdu 610041, Sichuan, China 